\title{
Phylogenetic relationships and evolutionary history of the greater horseshoe bat, Rhinolophus ferrumequinum, in Northeast Asia
}

\author{
Tong Liu ${ }^{1}$, Keping Sun ${ }^{\text {Corresp.. }}{ }^{1}$, Yung Chul Park ${ }^{2}$, Jiang Feng ${ }^{\text {Corresp. } 1}$ \\ 1 Jilin Key Laboratory of Animal Resource Conservation and Utilization, Northeast Normal University, Changchun, China \\ 2 Department of Forest Environment Protection, College of Forest and Environmental Science, Kangwon National University, Chuncheon, South Korea \\ Corresponding Authors: Keping Sun, Jiang Feng \\ Email address: sunkp129@nenu.edu.cn, fengj@nenu.edu.cn
}

The greater horseshoe bat, Rhinolophus ferrumequinum, is an important model organism for studies on chiropteran phylogeographic patterns. Previous studies revealed the population history of $R$. ferrumequinum from Europe and most Asian regions, yet there continue to be arguments about their evolutionary process in Northeast Asia. In this study, we obtained mitochondrial DNA cyt $b$ and D-loop data of $R$. ferrumequinum from Northeast China, South Korea and Japan to clarify their phylogenetic relationships and evolutionary process. Our results indicate a highly supported monophyletic group of Northeast Asian greater horseshoe bats, in which Japanese populations formed a single clade and clustered into the mixed branches of Northeast Chinese and South Korean populations. We infer that $R$. ferrumequinum in Northeast Asia originated in Northeast China and South Korea during a cold glacial period, while some ancestors likely arrived in Japan by flying or land bridge and subsequently adapted to the local environment. Consequently, during the warm Eemian interglaciation, the Korea Strait, between Japan and South Korea, became a geographical barrier to Japanese and inland populations, while the Changbai Mountains, between China and North Korea, did not play a significant role as a barrier between Northeast China and South Korea populations. 
1 Phylogenetic relationships and evolutionary history of the greater horseshoe

2 bat, Rhinolophus ferrumequinum, in Northeast Asia

3 Tong Liu ${ }^{1}$, Keping Sun ${ }^{1 *}$, Yung Chul Park ${ }^{2}$, Jiang Feng ${ }^{1 *}$

$4{ }^{1}$ Jilin Provincial Key Laboratory of Animal Resource Conservation and Utilization,

5 Northeast Normal University, Changchun, China

$6{ }^{2}$ Department of Forest Environment Protection, College of Forest and

7 Environmental Science, Kangwon National University, Chuncheon 200-701, South

8 Korea.

9 Abstract The greater horseshoe bat, Rhinolophus ferrumequinum, is an important

10 model organism for studies on chiropteran phylogeographic patterns. Previous

11 studies revealed the population history of $R$. ferrumequinum from Europe and most

12 Asian regions, yet there continue to be arguments about their evolutionary process

13 in Northeast Asia. In this study, we obtained mitochondrial DNA cyt $b$ and D-loop

14 data of $R$. ferrumequinum from Northeast China, South Korea and Japan to clarify

15 their phylogenetic relationships and evolutionary process. Our results indicate a

16 highly supported monophyletic group of Northeast Asian greater horseshoe bats, in

17 which Japanese populations formed a single clade and clustered into the mixed

18 branches of Northeast Chinese and South Korean populations. We infer that $R$.

19 ferrumequinum in Northeast Asia originated in Northeast China and South Korea

20 during a cold glacial period, while some ancestors likely arrived in Japan by flying

21 or land bridge and subsequently adapted to the local environment. Consequently,

22 during the warm Eemian interglaciation, the Korea Strait, between Japan and South 
23 Korea, became a geographical barrier to Japanese and inland populations, while the

24 Changbai Mountains, between China and North Korea, did not play a significant role as a barrier between Northeast China and South Korea populations.

\section{Introduction}

During the past 2.5 million years, Earth has been in glacial and interglacial periods of the Quaternary Ice Age (Capinera, 2011). Climatic change and the existence of refugia have influenced effective population size and demographic history of

31 organisms and left genetic signatures in current populations (Avise, 2000; Hewitt,

32 2000; Qu et al., 2014). The effective population size of organisms may decrease

33 during the glacial period or remain stable or grow due to intermittent gene flow

34 between refugia during warming periods (Li et al., 2009; Qu et al., 2014). The large

35 volume of accumulated ice during the most recent Quaternary glaciation period 36 caused a worldwide sea level drop by $120-140 \mathrm{~m}$ below the present sea level

37 (Lambeck et al., 2002). Land bridges appeared in several parts of the world, which 38 inevitably led to range changes for most living organisms (Hewitt, 2000).

39 Consequently, organisms adapted to different environments and new neighbors, 40 causing genetic variation, both through selection and drift, and ultimately speciation 41 (Harrison, 1993; Hewitt, 2000).

42 The greater horseshoe bat, Rhinolophus ferrumequinum (Rhinolophidae, 43 Rhinolophus), is widely distributed in northern Africa, southern Europe, and Asia 
44 (Csorba et al., 2003). In China, it ranges from northeastern to southwestern regions

45 (Wang, 2003). Previous studies have revealed the impact of glaciations on their geographic patterns in Europe and most Asian regions (Rossiter et al., 2000; Rossiter et al., 2007; Bilgin et al., 2009; Flanders et al., 2009; Flanders et al., 2011), but little is known about this species from Northeast Asia. Flanders et al. $(2009,2011)$ showed that $R$. ferrumequinum from the Jilin Province of China was affiliated with those from Japan, based on the mtDNA ND2 gene, which suggests greater horseshoe bats might move between east China and Japan using South Korea as a stepping-stone (Flanders et al., 2009) or by the Korean Peninsula-Japanese land bridge during glacial periods (Flanders et al., 2011). However, no Korean samples and only one sample from Jilin Province were analyzed in the Flanders et al. studies $(2009,2011)$. Their results indicated that the Jilin Province sample was located in the East clade of China, whereas Sun et al. (2013) showed that all samples from the Jilin Province were divided into another Northeast clade based on the mtDNA D-loop region. Therefore, it is necessary to combine more samples from Northeast China, South Korea and Japan to investigate the population evolutionary process of $R$. ferrumequinum in Northeast Asia.

Natural landscape features, such as mountains and rivers, can function as genetic

62 boundaries and shape the population structure of animals by hindering dispersal and 3 gene flow (Funk et al., 2008; Bilgin et al., 2009; Fünfstück et al., 2014). For $R$. ferrumequinum in Northeast Asia, the Yalu River and Changbai Mountains 
65 separated the populations from Northeast China and Korean Peninsula. Additionally,

66 the Korea Strait separated the populations in Korea from those in Japan. Koh et al.

67 (2014) considered that the Yalu River and Changbai Mountains did not play a role

68 as physical barriers for Korean and adjacent Northeast Chinese populations in $R$.

69 ferrumequinum based on mtDNA cyt $b$ gene. However, only one sample from

70 Northeast China was included in their analyses.

71 In this study, we collected and sequenced mtDNA cyt $b$ and D-loop sequences of

72 additional $R$. ferrumequinum samples from Northeast China and South Korea, and

73 analyzed them with all of the previously published mtDNA sequences from China,

74 Japan and South Korea. Our aims were to (i) clarify the phylogenetic relationships

75 of $R$. ferrumequinum in Northeast Asia, (ii) infer the evolutionary process in

76 Northeast Asia, and (iii) detect whether the Changbai Mountains and Korea Strait

77 act as geographical barriers for $R$. ferrumequinum.

\section{Materials and methods}

R. ferrumequinum individuals were sampled from Northeast China and South Korea.

Twenty-two and 49 individuals were used to sequence mtDNA cyt $b$ and D-loop region, respectively. A total of 76 sequences (63 cyt $b$ sequences and 13 D-loop sequences) of $R$. ferrumequinum were collected from Japan, South Korea and China (Fig.1; Table S1, supporting information). For the D-loop region, our study did not

85 include the sequences from Japan because no D-loop sequence of Japanese $R$. 
86 ferrumequinum was deposited in GenBank. All field studies were approved by

87 National Animal Research Authority in Northeast Normal University, China 88 (approval number: NENU-20080416).

89 Previous studies and this study show South Korean, Japanese and Northeast Chinese

$90 R$. ferrumequinum have very low genetic divergence (Sakai et al., 2003; Koh et al.,

91 2014). Therefore, we regard bats from South Korea, Japan or Northeast China as a

92 single geographic population.

\section{DNA extraction and amplification}

Bats' wing membrane tissues were taken and stored at 95\% ethanol solution until genome extraction by the UNIQ-10 Column Animal Genomic DNA Isolation Kit (SK1205) (Sangon, China). Mitochondrial DNA cyt $b$ and D-loop region were amplified by polymerase chain reaction (PCR) using universal primers L14724 and H15915 (Irwin et al., 1991) and P and E (Wilkinson \& Chapman, 1991), respectively. Amplified products were purified and sequenced by Shanghai Sangon Biotechnology Co., Ltd. Sequences were edited and aligned using Geneious v8.0.2 (Kearse et al., 2012), and then were assembled by eye. Sequence data were deposited in GenBank (accession number: KX237527-KX237538 and KX237546).

\section{Genetic diversity}

Haplotype diversity, nucleotide diversity and polymorphic sites of each population were calculated based on cyt $b$ and D-loop sequences, respectively. The gene flow 
107 was calculated using cyt $b$ gene sequences based on the equation: Fst $=1 /(1+$

108 4Nm). All calculations were carried out using DnaSP v4.0 (Rozas et al., 2003).

109 Pairwise distances between populations were obtained using Kimura-2-Parameter

110 (K2P) distance model (Kimura, 1980), with 1,000 bootstrap replications, using

111 MEGA v5.0 (Tamura et al., 2013).

\section{Phylogenetic analysis}

113 Phylogenetic trees of cyt $b$ and D-loop were reconstructed using maximum

114 likelihood (ML) methods in PhyML v3.1 (Guindon et al., 2010) and Bayesian

115 Inference (BI) in MrBayes v3.2.2 (Ronquist \& Huelsenbeck, 2001; Ronquist \&

116 Huelsenbeck, 2003). PhyML starts with a BioNJ tree by default (Gascuel, 1997),

117 and statistical support for branching patterns was estimated by bootstrap with 1,000

118 replicates. BI was run with four Markov Chains Monte Carlo (MCMC), each of

$1191 \times 10^{7}$ generations, sampled every 100 generations. Two congeneric species from the

120 Afro-Paleartic clade, Rhinolophus euryale (GenBank nos. EU436671 and

121 KF031268) and R. fumigatus (GenBank nos. EU436678 and KU531336) were used

122 as outgroups.

$123 \mathrm{ML}$ and BI methods are sensitive to nucleotide substitution models, which can be

124 estimated by jModelTest v0.1 (Posada, 2008). According to the Akaike information

125 criterion (AIC) (Posada \& Buckley, 2004), the HKY + G (transition/transversion $=$

12.9820; gamma shape $=0.1510)$ and $\mathrm{HKY}+\mathrm{G}($ transition $/$ transversion $=4.5832$

gamma shape $=0.1840$ ) were selected for cyt $b$ and D-loop, respectively. 
128 The program NETWORK v4.6 (Bandelt et al., 1999) was used to build a maximum

129 parsimony network using the median-joining method, which simplified same-

130 possible trees and removed redundant nodes and connections (Puizina et al., 2013),

131 as well as represented the intraspecific genetic variation (Posada \& Crandall, 2001).

132 In order to estimate divergent time, the time to the most recent common ancestor

133 (TMRCA) was estimated using BEAST v1.6 (Drummond \& Rambaut, 2007) under

134 a strict clock and a constant-size tree prior. The chain was run for $1 \times 10^{7}$ generations,

135 with the ESS values $>200$ taken as evidence for convergence. Cyt $b$ gene was chosen

136 to calculate TMRCA because of its moderate evolutionary rate. A mean substitution

137 rate of $1.3 \%$ per million years (Nabholz et al., 2008), used in Hipposideros turpis

138 complex (Thong et al., 2012), Hipposideros commersoni (Rakotoarivelo et al.,

139 2015) and Myotis nattereri complex (Puechmaille et al., 2012), was used in this

140 analysis.

141 Demographic analysis

142 The demographic expansion of Northeast Asian R. ferrumequinum was examined in

143 Arlequin v3.1 (Schneider et al., 2000). Tajima's $D$ test (Tajima, 1989) and Fu's Fs

144 test $(\mathrm{Fu}, 1997)$ were employed to confirm neutral expectation based on 1,000

145 coalescent simulations. Significant negative Tajima's $D$ and Fu's $F s$ values indicate

146 a sudden expansion, whereas significant positive values indicate processes such as

147 population subdivision or recent bottlenecks. When the values are nearly zero, they

148 represent a population of constant size (Liao et al., 2010). The raggedness index 
149 (Hri; Harpending, 1994) and sum of squared deviations (SSD; Schneider \&

150 Excoffier, 1999) were generated with 10,000 replicates parametric bootstrapping.

151 Hri was calculated to describe the smoothness of observed mismatch distribution.

152 The small value means a population has experienced a sudden expansion event, and 153 the higher value indicates a stationary or bottlenecked population (Harpending, 154 1994; Liao et al., 2010). SSD value was used to describe the goodness-of-fit of 155 observed mismatch distribution to that expected under the spatial expansion model.

156 A non-significant SSD value $\left(P_{\mathrm{SSD}}>0.05\right)$ suggests a good fitness (Excoffier et al., 157 2005). The mismatch distribution graphs were drawn in DnaSP v4.0. A smooth or 158 unimodal mismatch distribution indicates an expanded population, while a ragged 159 or multimodal distribution indicates a more stable population (Rogers \& 160 Harpending, 1992; Flanders et al., 2011).

161 If the expansion was detected, the time of expansion in generations $(t)$ can be 162 estimated by the equation, $\tau=2 u t$, where $\tau$ (tau) is the time to expansion in 163 mutational units and $u$ is the mutation rate per generation for the DNA sequence 164 being studied. Cyt $b$ mutation rate is $1.3 \%$ per million years (Nabholz et al., 2008), 165 and the generation time is two years (Ransome, 1995).

Results

168 Genetic diversity and divergence

169 A total of 85 sequences based on the cyt $b$ gene (1140 bp) and 62 sequences based 
170 on D-loop region (465 bp) were obtained and analyzed (Table S1, supporting 171 information). For the cyt $b$ gene, 15 different haplotypes were identified from 79 172 sequences of Northeast Asian $R$. ferrumequinum. The Japanese population had 7 173 unique haplotypes, while Chinese and South Korean populations shared haplotype $174 \mathrm{H} 15$, which was the most shared haplotype. For D-loop region, 10 unique haplotypes 175 were identified from 51 sequences of R. ferrumequinum in Northeast Asia. H9 was 176 shared by individuals from Ji'an and Benxi in Northeast China, whereas H10 was 177 shared by most individuals and populations (including individuals in all four 178 localities of China and some individuals in South Korea) (Table S2, supporting 179 information).

180 Within cyt $b$ and D-loop haplotypes, there were $15(1.3 \%)$ and $9(2.0 \%)$ polymorphic 181 sites, respectively, and $10(0.87 \%)$ and $5(1.1 \%)$ parsimonious informative sites, 182 respectively. Genetic diversity of the South Korean population was the highest, 183 while that of the Northeast Chinese population was the lowest (Table 1).

184 The cyt $b$ divergence of Northeast Asian $R$. ferrumequinum was lower than $1 \%$. The 185 average K2P distances between populations from Northeast China and South Korea $186(0.07 \%)$ were lower than those between Japanese and other Northeast Asian 187 populations $(0.21 \%-0.26 \%)$. Furthermore, the gene flow between South Korea and 188 Northeast China $(\mathrm{Nm} \geq 3)$ was highest, which was enough to prevent genetic 189 divergence caused by genetic drift (Slatkin, 1987; Yang et al., 2011). However, the 190 gene flow levels between Japanese and the other Northeast Asian populations were 
191 low (Table 2).

192 Phylogenetic relationships and TMRCA

193 The ML and BI tree topologies based on cyt $b$ gene produced highly concordant 194 phylogenetic relationships. All samples from Northeast Asia formed a highly 195 supported monophyletic clade (Fig. 2). In the tree, the relationship between 196 Northeast Chinese and South Korean haplotypes was much less resolved, likely due 197 to only a few mutations. Japanese haplotypes formed their own clade, but with 198 relatively low bootstrap values (62/79\% in $\mathrm{ML} / \mathrm{BI}$, respectively) (Fig. 2A). The Japanese clade clustered into the mixed branches of South Korean and Northeast

200 Chinese haplotypes. The haplotypes of Northeast Asia were sister to those of the 201 Central-East China (Fig. 2A). The haplotype network showed similar relationships 202 with the phylogenetic trees, while showing the relationship between the haplotypes 203 more clearly (Fig. 2B).

204 The noncoding D-loop region generally provides sufficient variation for studies at 205 intraspecific level (Qu et al., 2009). However, in the phylogenetic tree and haplotype 206 network based on D-loop region, the Northeast Chinese haplotypes were hardly 207 separated from South Korean haplotypes (Fig. 3).

208 The TMRCA of all examined R. ferrumequinum individuals could be dated to 1.87 $209 \mathrm{Ma}(95 \%$ CI 1.39-2.35 Ma). The TMRCA estimates obtained for Clade CE 210 China/Northeast Asia were 0.87 Ma (95\% CI 0.60-1.16 Ma). For East Asian $R$. 211 ferrumequinum, the TMRCA was $0.22 \mathrm{Ma}(95 \%$ CI 0.12-0.34 Ma), which could be 
212 traced back to the late Pleistocene.

\section{Historical demography}

214 Mismatch distribution analysis based on cyt $b$ revealed different historical 215 demography. Japanese and South Korean populations failed to reject the model of 216 population expansion based on $\operatorname{Hri}, \operatorname{SSD}\left(P_{\mathrm{SSD}}>0.05, P_{\mathrm{Hri}}>0.05\right)($ Table 3$)$ and their 217 smooth or unimodal mismatch distributions (Fig. S1, supporting information). The 218 significant negative Fu's $F s$ value also indicate a sudden expansion. The most recent 219 expansion times were estimated to be $0.15 \mathrm{Ma}(95 \% \mathrm{CI} 0.05-0.27 \mathrm{Ma})$ and $0.12 \mathrm{Ma}$ 220 (95\% CI 0.03-0.20 Ma) for Japanese and South Korean populations, respectively.

221 However, the high Hri, non-significant positive Fu's $F s$ value and multiple mismatch 222 distribution of Northeast Chinese population suggests a stable population history or 223 population bottlenecks (Liao et al., 2010) (Table 3, Fig S1, supporting information).

Discussion

Rhinolophus ferrumequinum from Northeast Asia diverged from other populations during 0.87-0.22 Ma, corresponding to the Quaternary Pleistocene (Ehlers et al., 228 2011). Climate fluctuations of this epoch played important roles in shaping the geographical distribution, historical demography and genetic diversification of many organisms in the Palaearctic region (Qu et al., 2009).

231 In this study, the TMRCA of the greater horseshoe bats from Northeast Asia could 232 date back to $0.22 \mathrm{Ma}(95 \%$ CI $0.12-0.34 \mathrm{Ma})$, during the Saale glaciation (0.13-0.30 
233 Ma) (Lisiecki \& Raymo, 2005). Accompanied with temperature dropping in this 234 period, the sea level declined gradually, and reached the lowest (about $130 \mathrm{~m}$ lower 235 than it is today) at 0.14 Ma (Rohling et al., 1998; Molodkov \& Bolikhovskaya, 236 2002), which could be beneficial for bats to cross the sea. Flanders et al. (2011) 237 suggested that greater horseshoe bats are most likely to have originated in the 238 Shandong Province of China. Therefore, we inferred that $R$. ferrumequinum might 239 disperse to Northeast China and South Korea from Shandong Province by the Bohai 240 Sea, as this is the shortest way and the Bohai Sea would have disappeared if the sea 241 level dropped 120 m (Ray \& Adams, 2001). Furthermore, haplotype network seemed 242 to support this scenario, where H15 is a more likely ancestor haplotype occupying 243 the center of the network with numerous connects (Fig. 2B).

244 In Northeast China, the population might have undergone a founder effect due to its 245 low genetic diversity. However, a specific haplotype H14 was detected in Northeast 246 China, which may be not congruent with this notion. Instead, combining the high Hri and non-significant positive Fu's $F s$ value, we inferred a bottlenecked event may have occurred in Northeast China (Liao et al., 2010). In regards to the South Korean 249 population, we compared previous studies on $R$. ferrumequinum (Flanders et al., 250 2011; Sun et al., 2013; Koh et al., 2014) and found an expanding event was first 251 detected at $0.12 \mathrm{Ma}(95 \% \mathrm{CI} 0.03-0.20 \mathrm{Ma})$, which corresponds to the relatively 252 warm Eemian interglaciation (0.12-0.13 Ma) in the Pleistocene.

253 The Changbai Mountains are the boundary of Northeast China and Korean 
254 Peninsula. Extremely low genetic divergence and high gene flow level between 255 populations from Northeast China and South Korea suggest that the Changbai 256 Mountains have not acted as a geographic barrier. In previous studies, Sun et al. 257 (2013) and Flanders et al. (2011) found the Qinling Mountains have played an 258 important role in forming different lineages of $R$. ferrumequinum bats; however, 259 Rossiter et al. (2007) considered the Pyrenees (above 2,000 m) have not hindered 260 gene flow of $R$. ferrumequinum, and Bilgin et al. (2009) showed the Taurus 261 Mountains and eastern Anatolian Diagonal Mountain Chain have not limited the 262 western clade of $R$. ferrumequinum bats' distribution. Therefore, the isolation effect 263 of different mountains is variable. Moreover, we cannot rule out other reasons, such 264 as incomplete lineage sorting and ancestral polymorphism, which can also cause low 265 divergence between populations from Northeast China and South Korea (Flanders 266 et al., 2009).

267 In our study, the Japanese population formed a single sub-clade and diverged more 268 recently than the populations from Northeast China and South Korea (Fig. 2A), 269 which is in contrast to the Flanders et al. studies (2009, 2011). Flanders et al. (2009) 270 considered that $R$. ferrumequinum colonized East China from Japan. However, our 271 results indicate that the Japanese population colonized more recently from Eurasian 272 continent. It was determined that the Korea Strait is about $130 \mathrm{~m}$ deep, so the land 273 bridge can only be formed during main glacial period (McKay, 2012). Ohshima 274 (1990) mentioned that the Korean Peninsula-Japanese land bridge was estimated to 
275 have remained in place until $0.15 \mathrm{Ma}$ (also see Watanobe, Ishiguro \& Nakano, 2003).

276 Thus, we inferred that the emergence of the land bridge favored some $R$. 277 ferrumequinum bats to colonize Japan from Northeast China and South Korea. 278 Additionally, other mammals, such as the Japanese wild boar (Sus scrofa 279 leucomystax) (Watanobe et al., 2003), sika deer (Cervus nippon) (Nagata et al., 280 1999) and Asian black bear (Ursus thibetanus) (Ohnishi et al., 2009) were found to 281 colonize Japan from Eurasian continent via the Korean Peninsula-Japanese land 282 bridge (Flanders et al., 2011).

283 However, some studies showed that Japan was not connected to Eurasian continent 284 during this period (Park et al., 2000; Ray \& Adams, 2001; Flanders et al., 2007). 285 There was a narrow seaway (about $20 \mathrm{~km}$ wide) in Korea Strait connecting the East 286 China Sea and the East Japan Sea (Park et al., 2000). Bats of $R$. ferrumequinum are 287 able to fly up to $30 \mathrm{~km}$ between the winter and summer roosts, with the longest 288 recorded movement being $180 \mathrm{~km}$ (Paz et al., 1986). Bilgin et al. (2009) found the 289 Marmara Sea $(70 \mathrm{~km})$ does not seem to limit the dispersal in $R$. ferrumequinum. 290 Although a narrow seaway would have been present, $R$. ferrumequinum from the 291 Eurasian continent could go through the Korea Strait and enter Japan during the 292 glacial period. Rhinolophus ferrumequinum in Japan might have expanded at 0.15 293 $\mathrm{Ma}(95 \% \mathrm{CI} 0.05-0.27 \mathrm{Ma})$, which is consistent with the expansion time (0.13-0.19 Ma) calculated by Flanders et al. (2011). This expansion time is in the Saale 295 glaciation, which suggests Japan might act as a refuge for mammals in Northeast 
296 Asia during glacial periods.

297 With the arrival of the Eemian interglaciation $(0.12-0.13 \mathrm{Ma})$, the temperature 298 increased gradually, resulting in rising sea levels. The Korea Strait became a natural 299 barrier which isolated Japanese $R$. ferrumequinum from other Eurasian continental 300 populations. Other studies also show gene flow can be hindered by water bodies, 301 such as the Taiwan Strait $(131 \mathrm{~km})$ and English Channel $(100 \mathrm{~km})($ Chen et al., 2006; 302 Rossiter et al., 2007). The wider Korea Strait $(180 \mathrm{~km})$ was inferred to play an 303 important role in acting as a barrier to hinder the gene flow between Japanese and 304 Eurasian continental populations.

\section{Acknowledgements}

307 We would like to thank Tinglei Jiang and Guanjun Lu who worked hard with us in 308 the field to collect the samples used in this study. We are especially grateful to Katy 309 Parise for her kind help with language modification. And we also thank Ying Tang 310 for the lab work. 


\section{Reference}

313 Avise JC. 2000. Phylogeography: the history and formation of species. Harvard: Harvard university press.

314 Bandelt HJ, Forster P, and Röhl A. 1999. Median-joining networks for inferring intraspecific phylogenies. Molecular Phylogenetics and Evolution 16:37-48.

Bilgin R, Çoraman E, Karataş A, and Morales JC. 2009. Phylogeography of the Greater Horseshoe Bat, Rhinolophus ferrumequinum (Chiroptera: Rhinolophidae), in Southeastern Europe and Anatolia, with a Specific Focus on Whether the Sea of Marmara is a Barrier to Gene Flow. Acta Chiropterologica 11:53-60.

Capinera J. 2011. Insects and wildlife: arthropods and their relationships with wild vertebrate animals. John Wiley \& Sons.

Chen Sf, Rossiter SJ, Faulkes CG, and Jones G. 2006. Population genetic structure and demographic history of the endemic Formosan lesser horseshoe bat (Rhinolophus monoceros). Molecular Ecology 15:1643-1656.

Csorba G, Ujhelyi P, and Thomas N. 2003. Horseshoe bats of the world:(Chiroptera: Rhinolophidae). Alana Books.

Drummond AJ, and Rambaut A. 2007. BEAST: Bayesian evolutionary analysis by sampling trees. BMC Evolutionary Biology 7:214.

Ehlers J, Gibbard PL, and Hughes PD. 2011. Quaternary glaciations-extent and chronology: a closer look. Elsevier.

Excoffier L, Laval G, and Schneider S. 2005. ARLEQUIN ver. 3.0: An integrated software package for population genetics data analysis. Evolutionary Bioinformatics 1:47-50.

Fünfstück T, Arandjelovic M, Morgan DB, Sanz C, Breuer T, Stokes EJ, Reed P, Olson SH, Cameron K, and Ondzie A. 2014. The genetic population structure of wild western lowland gorillas (Gorilla gorilla gorilla) living in continuous rain forest. American journal of primatology 76:868-878.

Flanders J, Jones G, Benda P, Dietz C, Zhang S, Li G, Sharifi M, and Rossiter SJ. 2009. Phylogeography of the greater horseshoe bat, Rhinolophus ferrumequinum: contrasting results from mitochondrial and microsatellite data. Molecular Ecology 18:306-318.

Flanders J, Wei L, Rossiter SJ, and Zhang S. 2011. Identifying the effects of the Pleistocene on the greater horseshoe bat, Rhinolophus ferrumequinum, in East Asia using ecological niche modelling and phylogenetic analyses. Journal of Biogeography 38:439-452.

Fu YX. 1997. Statistical tests of neutrality of mutations against population growth, hitchhiking and background selection. Genetics 147:915-925.

Funk WC, Forsman ED, Mullins TD, and Haig SM. 2008. Landscape features shape genetic structure in threatened Northern Spotted Owls. US : Geological Survey (US).

Gascuel O. 1997. BIONJ: an improved version of the NJ algorithm based on a simple model of sequence data. molecular biology and evolution 14:685-695.

Guindon S, Dufayard JF, Lefort V, Anisimova M, Hordijk W, and Gascuel O. 2010. New algorithms and methods to estimate maximum-likelihood phylogenies: assessing the performance of PhyML 3.0. Systematic biology 59:307-321.

Harpending H. 1994. Signature of ancient population growth in a low-resolution mitochondrial DNA mismatch distribution. Human biology:591-600.

Harrison RG. 1993. Hybrid zones and the evolutionary process. Oxford: Oxford University Press on Demand.

Hewitt G. 2000. The genetic legacy of the Quaternary ice ages. NATURE 405:907-913.

Irwin DM, Kocher TD, and Wilson AC. 1991. Evolution of the cytochromeb gene of mammals. Journal of molecular 
evolution 32:128-144.

Kearse M, Moir R, Wilson A, Stones-Havas S, Cheung M, Sturrock S, Buxton S, Cooper A, Markowitz S, and Duran C. 2012. Geneious Basic: an integrated and extendable desktop software platform for the organization and analysis of sequence data. Bioinformatics 28:1647-1649.

Kimura M. 1980. A simple method for estimating evolutionary rates of base substitutions through comparative studies of nucleotide sequences. Journal of molecular evolution 16:111-120.

Koh HS, Jo JE, Oh JG, Kweon GH, Ahn NH, Sin WH, and Sin DS. 2014. Little genetic divergence of the greater horseshoe bat Rhinolophus ferrumequinum from far-eastern Asia, with a preliminary report on genetic differentiation of $R$. ferrumequinum from Eurasia and northern Africa examined from cytochrome $b$ sequences. RUSSIAN JOURNAL OF THERIOLOGY 13:97-103.

Lambeck K, Esat TM, and Potter E-K. 2002. Links between climate and sea levels for the past three million years. NATURE 419:199-206.

Li SH, Yeung CL, Feinstein J, Han L, Le MH, Wang CX, and Ding P. 2009. Sailing through the Late Pleistocene: unusual historical demography of an East Asian endemic, the Chinese Hwamei (Leucodioptron canorum canorum), during the last glacial period. Molecular Ecology 18:622-633.

Liao PC, Kuo DC, Lin CC, Ho KC, Lin TP, and Hwang SY. 2010. Historical spatial range expansion and a very recent bottleneck of Cinnamomum kanehirae Hay. (Lauraceae) in Taiwan inferred from nuclear genes. BMC Evolutionary Biology 10(1):1.

Lisiecki LE, and Raymo ME. 2005. A Pliocene-Pleistocene stack of 57 globally distributed benthic $\delta^{18} \mathrm{O}$ records. Paleoceanography 20:n/a-n/a.

McKay BD. 2012. A new timeframe for the diversification of Japan's mammals. Journal of Biogeography 39:11341143.

Molodkov AN, and Bolikhovskaya NS. 2002. Eustatic sea-level and climate changes over the last 600 ka as derived from mollusc-based ESR-chronostratigraphy and pollen evidence in Northern Eurasia. Sedimentary Geology 150:185-201.

Nabholz B, Glemin S, and Galtier N. 2008. Strong Variations of Mitochondrial Mutation Rate across Mammals-the Longevity Hypothesis. molecular biology and evolution 25:120-130.

Nagata J, Masuda R, Tamate HB, Hamasaki S-i, Ochiai K, Asada M, Tatsuzawa S, Suda K, Tado H, and Yoshida MC. 1999. Two genetically distinct lineages of the sika deer, Cervus nippon, in Japanese islands: Comparison of mitochondrial D-loop region sequences. Molecular Phylogenetics and Evolution 13:511-519.

Ohnishi N, Uno R, Ishibashi Y, Tamate H, and Oi T. 2009. The influence of climatic oscillations during the Quaternary Era on the genetic structure of Asian black bears in Japan. Heredity 102:579-589.

Ohshima K. 1990. The history of straits around the Japanese Islands in the late-Quaternary. The Quaternary Research 29:193-208.

Park S-C, Yoo D-G, Lee C-W, and Lee E-I. 2000. Last glacial sea-level changes and paleogeography of the Korea (Tsushima) Strait. Geo-Marine Letters 20:64-71.

Paz Od, Fernandez R, and Benzal J. 1986. El anillamiento de quiropteros en el centro de la peninsula iberica durante el periodo 1977-86. Bolentin de la Estacion Central de Ecologica 30:113-138.

Posada D. 2008. jModelTest: phylogenetic model averaging. molecular biology and evolution 25:1253-1256.

Posada D, and Buckley TR. 2004. Model selection and model averaging in phylogenetics: advantages of Akaike information criterion and Bayesian approaches over likelihood ratio tests. Systematic biology 53:793-808. 
Posada D, and Crandall KA. 2001. Selecting the best-fit model of nucleotide substitution. Systematic biology 50:580601.

Puechmaille SJ, Allegrini B, Boston ESM, Dubourg-Savage M-J, Evin A, Knochel A, Bris YL, Lecoq V, Lemaire M, Rist D, and Teeling EC. 2012. Genetic analyses reveal further cryptic lineages within the Myotis nattereri species complex. Mammalian Biology 77:224-228.

Puizina J, Puljas S, Fredotović Ž, Šamanić I, and Pleslić G. 2013. Phylogenetic Relationships among Populations of the Vineyard Snail Cernuella virgata (Da Costa, 1778). ISRN Zoology 2013.

Qu J, Liu N, Bao X, and Wang X. 2009. Phylogeography of the ring-necked pheasant (Phasianus colchicus) in China. Molecular Phylogenetics and Evolution 52:125-132.

Qu Y, Zhao Q, Lu H, and Ji X. 2014. Population Dynamics Following the Last Glacial Maximum in Two Sympatric Lizards in Northern China. Asian Herpetological Research 5:213-227.

Rakotoarivelo AR, Willows-Munro S, Schoeman MC, Lamb JM, and Goodman SM. 2015. Cryptic diversity in Hipposideros commersoni sensu stricto (Chiroptera: Hipposideridae) in the western portion of Madagascar. BMC Evolutionary Biology 15(1):1.

Ransome RD. 1995. Earlier breeding shortens life in female greater horseshoe bats. Philosophical Transactions of the Royal Society of London B: Biological Sciences 350:153-161.

Ray N, and Adams JM. 2001. A GIS-based vegetation map of the world at the Last Glacial Maximum (25,000-15,000 BP). Internet Archaeology 11.

Rogers AR, and Harpending H. 1992. Population growth makes waves in the distribution of pairwise genetic differences. Molecular Biology \& Evolution 9:552-569.

Rohling EJ, Fenton M, Jorissen FJ, Bertrand P, Ganssen G, and Caulet JP. 1998. Magnitudes of sea-level lowstands of the past 500,000 years. NATURE 394:162-165.

Ronquist F, and Huelsenbeck JP. 2001. MRBAYES: Bayesian inference of phylogenetic trees. Bioinformatics 17:754755.

Ronquist F, and Huelsenbeck JP. 2003. MrBayes 3: Bayesian phylogenetic inference under mixed models. Bioinformatics 19:1572-1574.

Rossiter SJ, Benda P, Dietz CN, Zhang S, and Jones G. 2007. Rangewide phylogeography in the greater horseshoe bat inferred from microsatellites: implications for population history, taxonomy and conservation. Molecular Ecology 16:4699-4714.

Rossiter SJ, Jones G, Ransome RD, and Barratt EM. 2000. Genetic variation and population structure in the endangered greater horseshoe bat Rhinolophus ferrumequinum. Molecular Ecology 9:1131-1135.

Rozas J, Sánchez-DelBarrio JC, Messeguer X, and Rozas R. 2003. DnaSP, DNA polymorphism analyses by the coalescent and other methods. Bioinformatics 19:2496-2497.

Sakai T, Kikkawa Y, and Tsuchiya K. 2003. Molecular phylogeny of Japanese Rhinolophidae based on variations in the complete sequence of the mitochondrial cytochrome b gene. Genes \& Genetic Systems 78:179-189.

Schneider S, and Excoffier L. 1999. Estimation of past demographic parameters from the distribution of pairwise differences when the mutation rates vary among sites: application to human mitochondrial DNA. Genetics 152:1079-1089.

Schneider S, Roessli D, and Excoffier L. 2000. Arlequin: a software for population genetics data analysis. User manual ver 2:2496-2497.

Slatkin M. 1987. Gene flow and the geographic structure of natural populations. Science 236:787-792. 
434

435

436

437

438

439

440

441

442

443

444

445

446

447

448

449

450

451

452

453
Sun K, Luo L, Kimball RT, Wei X, Jin L, Jiang T, Li G, and Feng J. 2013. Geographic Variation in the Acoustic Traits of Greater Horseshoe Bats: Testing the Importance of Drift and Ecological Selection in Evolutionary Processes. Plos one 8:e70368.

Tajima F. 1989. Statistical method for testing the neutral mutation hypothesis by DNA polymorphism. Genetics 123:585-595.

Tamura K, Stecher G, Peterson D, Filipski A, and Kumar S. 2013. MEGA6: molecular evolutionary genetics analysis version 6.0. molecular biology and evolution:mst197.

Thong VD, Puechmaille SJ, Denzinger A, Bates PJJ, Dietz C, Csorba G, Soisook P, Teeling EC, Matsumura S, Furey NM, and Schnitzler H-U. 2012. Systematics of the Hipposideros turpis complex and a description of a new subspecies from Vietnam. mammal review 42:166-192.

Wang Y. 2003. A complete checklist of mammal species and subspecies in China: a taxonomic and geographic reference. China: China Forestry Publishing House.

Watanobe T, Ishiguro N, and Nakano M. 2003. Phylogeography and Population Structure of the Japanese Wild Boar Sus scrofa leucomystax : Mitochondrial DNA Variation. ZOOLOGICAL SCIENCE 20:1477-1489.

Wilkinson GS, and Chapman AM. 1991. Length and sequence variation in evening bat D-loop mtDNA. Genetics 128:607-617.

Yang M, Ma Y, and Wu J. 2011. Mitochondrial genetic differentiation across populations of the malaria vector Anopheles lesteri from China (Diptera: Culicidae). Malaria journal 10:216. 
Figure 1 (on next page)

Sampling localities of Rhinolophus ferrumequinum in this study.

The colors of sampling points fit with clades identified in Fig. 2. Locality codes are identical to those in Table S1 (Supporting information). The map was freely reused and modified under the terms of the GNU Free Documentation License, Version 1.2. 
PeerJ

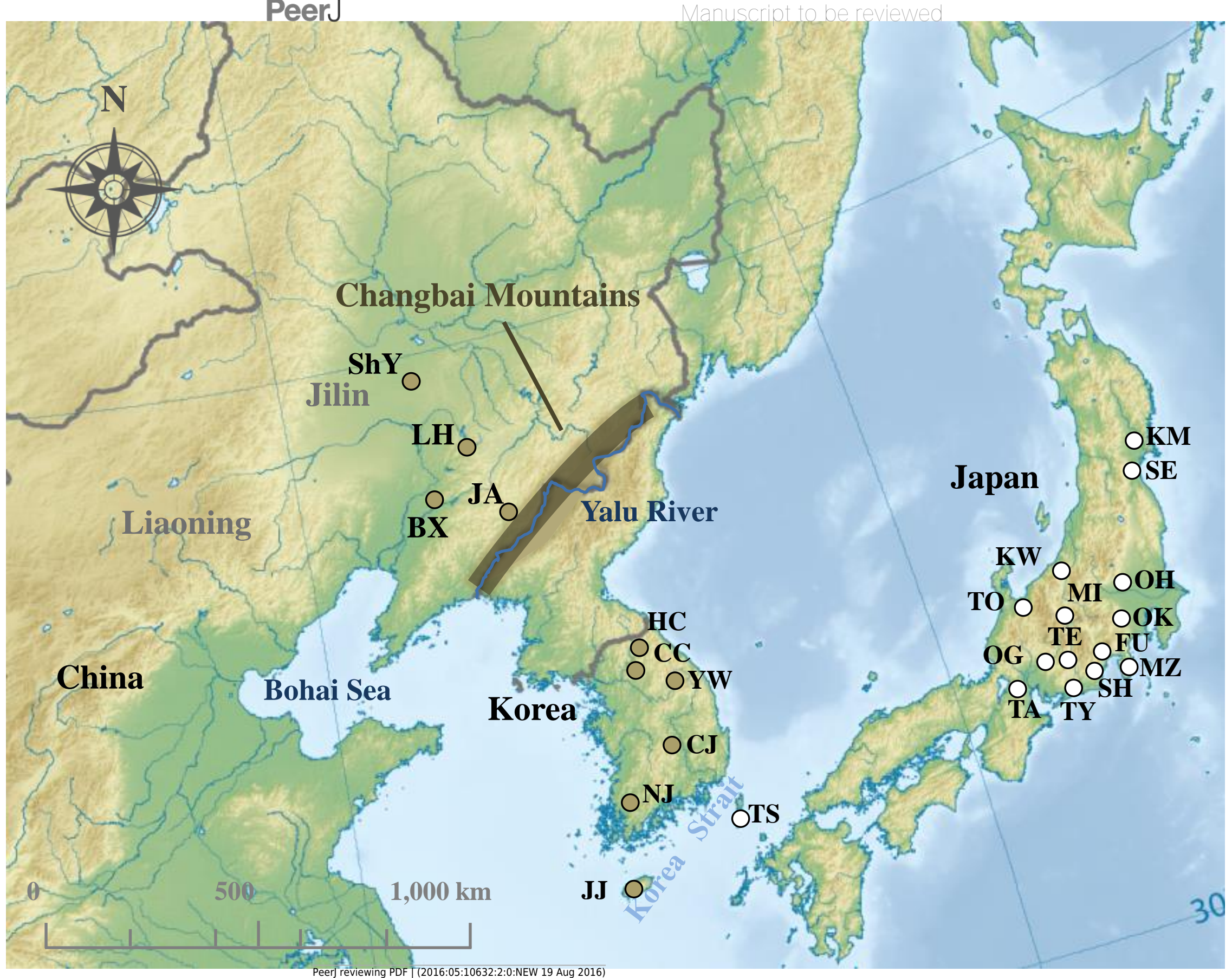


Figure 2 (on next page)

Phylogenetic trees and network for Rhinolophus ferrumequinum populations based on cyt $b$ haplotypes.

(A) Phylogenetic trees constructed by ML and BI methods. (B) Median-joining network for the East Asian $R$. ferrumequinum haplotypes. The circle size is proportional to the frequency of that haplotype. Small black dots represent missing haplotypes. Locality codes and haplotype are described in Table S1 and Table S2 (Supporting information), respectively. 


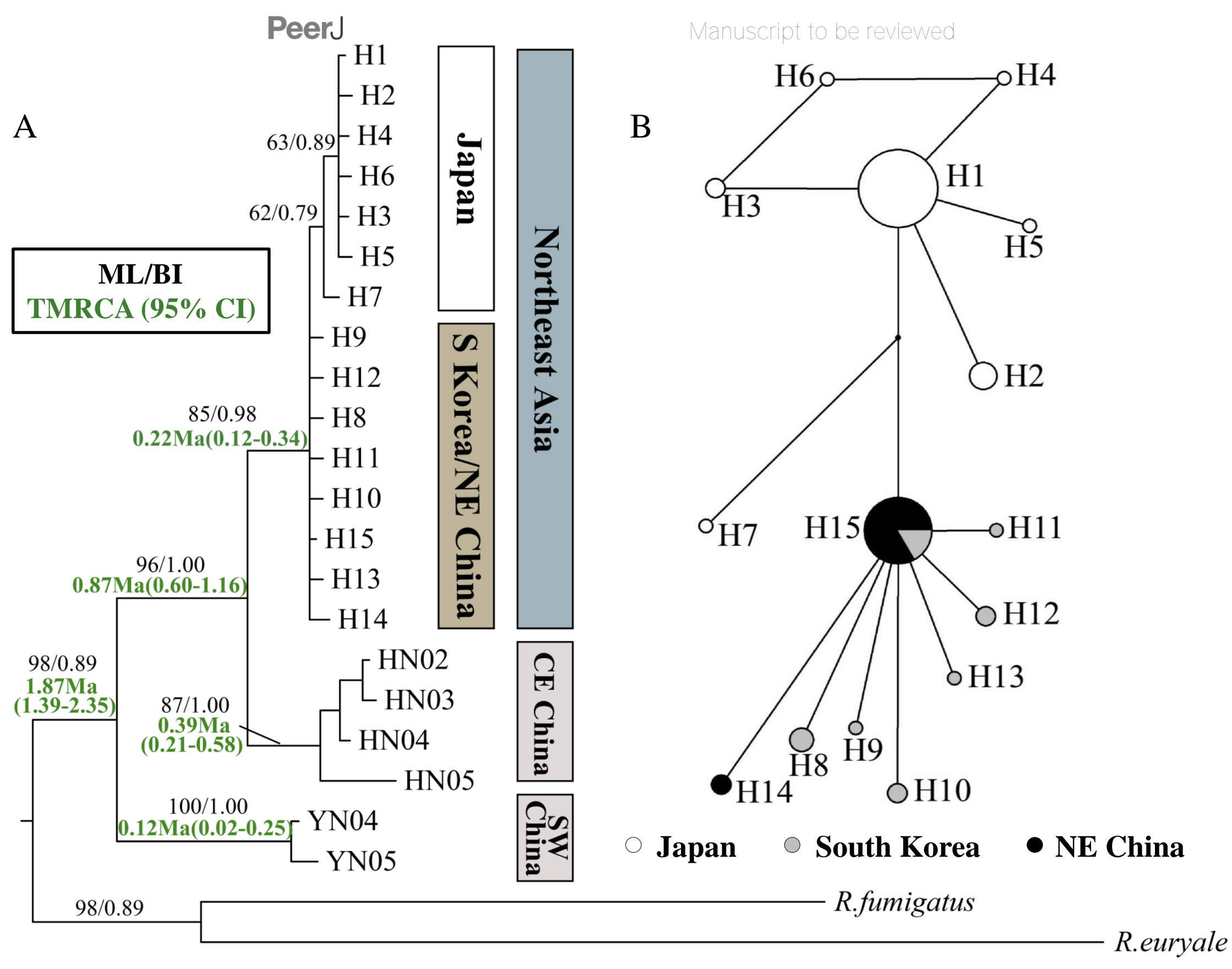


Figure 3 (on next page)

Phylogenetic trees and network for Rhinolophus ferrumequinum populations based on D-loop haplotypes.

(A) Phylogenetic trees constructed by ML and BI methods. The D-loop data of Japanese population was unavailable. (B) Median-joining network for the South Korean and Northeast Chinese $R$. ferrumequinum haplotypes. The circle size is proportional to the frequency of that haplotype. Small black dots represent missing haplotypes. Locality codes and haplotype are described in Table S1 and Table S2 (Supporting information), respectively. 


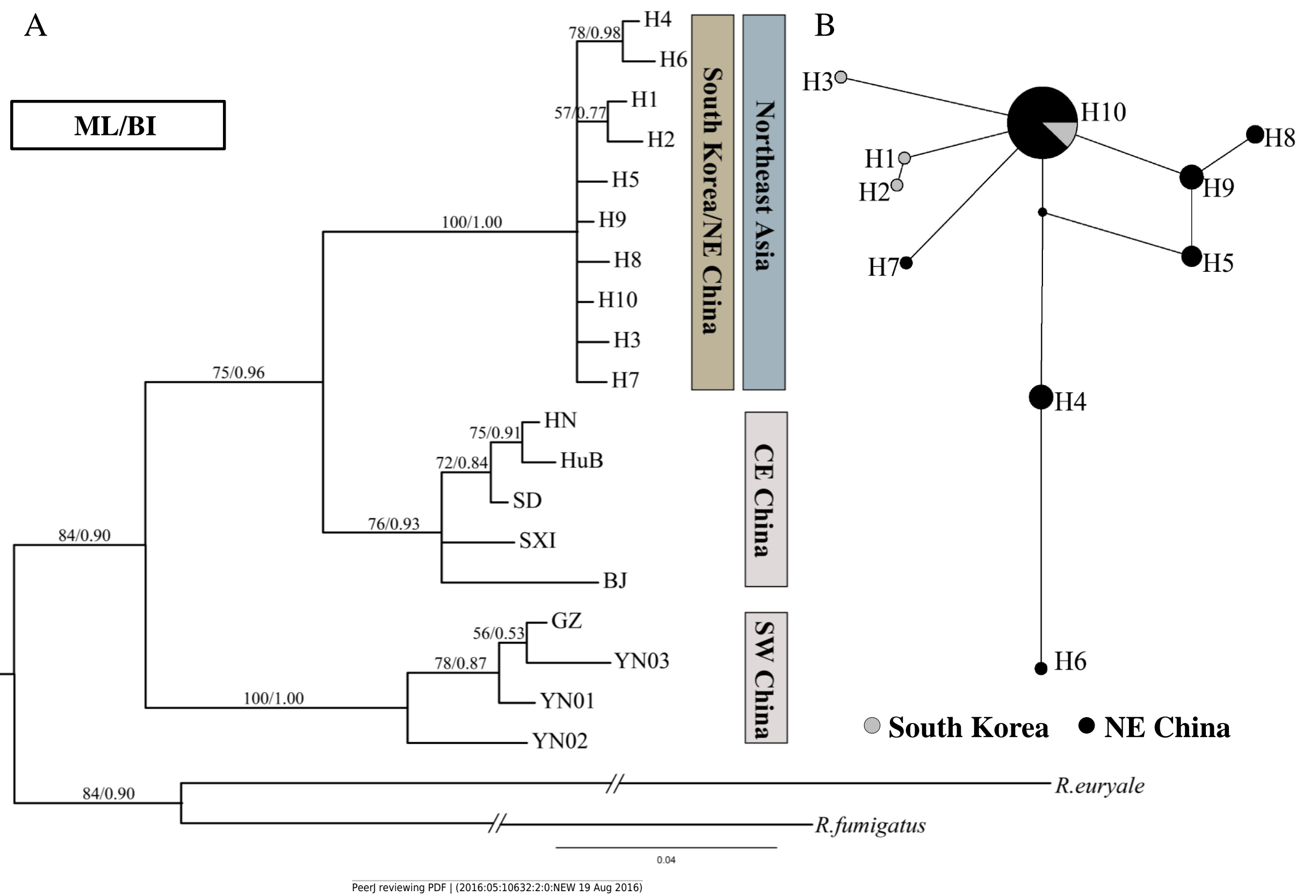




\section{Table 1 (on next page)}

Genetic diversity of Rhinolophus ferrumequinum in Northeast Asia. 
1 Table 1 Genetic diversity of Rhinolophus ferrumequinum in Northeast Asia.

\begin{tabular}{cccccc}
\hline & $N_{s}$ & $N_{h}$ & $N_{s s}$ & $h(c y t b / D-l o o p)$ & $\pi(c y t b / D-l o o p)$ \\
\hline $\begin{array}{c}\text { NE China } \\
\text { South }\end{array}$ & $22 / 43$ & $2 / 7$ & $2 / 6$ & $0.173 / 0.564$ & $0.030 / 0.226$ \\
$\begin{array}{c}\text { Korea } \\
\text { Japan }\end{array}$ & $14 / 8$ & $7 / 4$ & $6 / 3$ & $0.879 / 0.648$ & $0.116 / 0.201$ \\
$\begin{array}{c}\text { Northeast } \\
\text { Asia }\end{array}$ & $79 /-$ & $7 /-$ & $6 /-$ & $0.408 /-$ & $0.047 /-$ \\
\hline
\end{tabular}

$2 N_{s}$, the number of sequences; $N_{h}$, the number of haplotypes; $N_{s s}$, the number of segregating sites;

$3 h$, haplotype diversity; $\pi$, nucleotide diversity; -, missing data. 


\section{Table 2 (on next page)}

Average K2P distance (\%) and gene flow of Rhinolophus ferrumequinum based on cyt $b$ sequences. 
1 Table 2 Average K2P distance (\%) and gene flow of Rhinolophus ferrumequinum based on cyt $b$

2 sequences.

\begin{tabular}{cccccc}
\hline Population & $\begin{array}{c}\text { NE } \\
\text { China }\end{array}$ & $\begin{array}{c}\text { South } \\
\text { Korea }\end{array}$ & Japan & Henan & Yunnan \\
\hline NE China & & 3.11 & 0.06 & 0.06 & 0.01 \\
South Korea & 0.07 & & 0.11 & 0.06 & 0.01 \\
Japan & 0.21 & 0.26 & & 0.05 & 0.01 \\
Henan & 1.44 & 2.01 & 2.15 & & 0.03 \\
Yunnan & 3.96 & 4.02 & 4.17 & 4.27 & \\
\hline
\end{tabular}

3 Nm: above the diagonal; Average K2P distance (\%): below the diagonal. 


\section{Table 3(on next page)}

Results of mismatch distribution analyses and neutrality tests for Rhinolophus ferrumequinum based on cyt $b$ sequences. 
1 Table 3 Results of mismatch distribution analyses and neutrality tests for Rhinolophus

2 ferrumequinum based on cyt $b$ sequences.

\begin{tabular}{|c|c|c|c|c|c|c|}
\hline & SSD & Hri & $\begin{array}{c}\text { Tau } \\
(95 \% C I)\end{array}$ & $t(95 \% \mathrm{CI})$ & Tajima's $D$ & Fu's Fs \\
\hline NE China & 0.04 & 0.74 & $\begin{array}{c}3.00 \\
(0.55-3.00)\end{array}$ & - & -0.84 & 0.81 \\
\hline $\begin{array}{l}\text { South } \\
\text { Korea }\end{array}$ & 0.07 & 0.35 & $\begin{array}{c}1.71 \\
(0.43-2.98)\end{array}$ & $\begin{array}{c}0.12 \mathrm{Ma}(0.03- \\
0.20 \mathrm{Ma})\end{array}$ & $-1.73^{*}$ & $-5.26 * *$ \\
\hline Japan & 0.04 & 0.16 & $\begin{array}{c}2.27 \\
(0.75-3.94) \\
\end{array}$ & $\begin{array}{c}0.15 \mathrm{Ma}(0.05- \\
0.27 \mathrm{Ma})\end{array}$ & -0.73 & $-5.58 * *$ \\
\hline
\end{tabular}

3 Hri, raggedness index; SSD, sum of squared deviations; NA, data deficiencies; -, no expansion

4 was detected; statistically significant results were indicated by asterisks: $* P<0.05$, ** $P<0.01$. 